\title{
RIQUEZA E DESIGUALDADES
}

\author{
Antonio David Cattani
}

\begin{abstract}
Neste artigo, são analisadas as principais características e significados de um segmento específico dos detentores de altas fortunas provenientes da extração da riqueza na economia globalizada. Milionários e bilionários são designados pelos gestores financeiros como High Net Worth Individuals (HNWIs). Eles não constituem uma classe social com identidade, coesão e mobilização coletiva a partir de interesses homogêneos e articulados. Mas, como componentes dos setores dominantes internacionalizados, eles possuem alto poder econômico e político, com impactos significativos sobre a realidade social. Os HNWIs estão no centro do processo de agudização das desigualdades socioeconômicas nos últimos 20 anos e se caracterizam por três aspectos: a) desvinculação de dimensões físicas do capital e ausência de amarras nacionais; b) personificação das fortunas; c) faustuoso padrão de vida, que contrasta, de maneira acentuada, com o restante da população. O argumento central deste artigo é que, ao se analisar a estrutura social, é necessário considerá-la como um todo integrado e articulado, pois os polos riqueza e pobreza não são autoexplicativos e, menos ainda, autônomos. Considerando-se a importância da escala na posse da riqueza, é possível entender como ela assegura impunidade, privilégios e poder para minorias específicas, ampliando as desigualdades e a produção da pobreza.
\end{abstract}

PALAVRAS-CHAVE: riqueza, poder, classes sociais, desigualdades socioeconômicas.

As desigualdades são indispensáveis para o bom funcionamento do sistema capitalista, pois elas são criadas e recriadas permanentemente como forma de assegurar a vitalidade e o dinamismo da economia de mercado. Equilíbrio, igualitarismo social, justiça e bem comum são conquistas dos movimentos populares e dos trabalhadores organizados, e não frutos produzidos pela iniciativa privada sob a forma empresarial na esfera do mercado concorrencial. Quanto maiores forem as diferenças socioeconômicas entre os indivíduos, maior será sua desagregação, e, consequentemente, sua vulnerabilidade à dominação de grupos poderosos e à exploração. O mesmo acontece entre as empresas, uma vez que a diferença entre o poderio das mega corporações e as demais empresas garante às primeiras o domínio sobre mercados e consumidores, em detrimento dos capitalistas organizados em menor escala.

* Professor titular de Sociologia do Departamento de Sociologia e do Programa de Pós-Graduação em Sociologia da UFRGS. Doutor pela Université de Paris I PanthéonSorbonne. Pesquisador 1-A do CNPq.

Av. Bento Gonçalves, n. 9500, Campus do Vale. Cep: 91509-900. Porto Alegre - Rio Grande do Sul - Brasil. www.antoniodavidcattani.net
A atual crise econômica, a mais grave nos últimos 80 anos, evidencia, de maneira inconteste, essa análise. A extraordinária expansão da esfera produtiva ocorrida a partir de meados da década de 1980 esteve associada, de maneira clara e objetiva, ao crescimento exponencial das desigualdades em múltiplas dimensões. A liberdade do e pelo capital, que impulsionou as transformações durante os últimos 25 anos, resultou no aprofundamento negativo da brecha social e econômica, em outros termos, nas distâncias entre ricos e grandes empresas do restante da população e do capitalismo de menor escala. Longe de ser elemento de construção de um mundo mais justo e equilibrado, a geração de um volume maior de riqueza significou mais pobreza absoluta e relativa, ou seja, maiores desigualdades.

A globalização intensificada fez com que especificidades nacionais passassem para um segundo plano. Por isso, os desdobramentos concretos dos grandes movimentos econômicos, das estratégias corporativas e das lutas pela apropriação do excedente devem ser considerados, primeiramente, na sua manifestação mundial e, após, em termos locais. Pode-se dizer que o processo de concentração de ren- 
da foi planetário, consolidando-se em países tradicionalmente desiguais como o Brasil (Santos, 2002), e até mesmo em países considerados igualitários como a Suécia (Waldenström, 2006). Os grandes números apresentados a seguir serão reforçados pela referência a alguns casos exemplares que, embora selecionados arbitrariamente do noticiário econômico recente, não são aleatórios ou excepcionais.

As desigualdades são claramente expostas num importante estudo produzido pela Universidade das Nações Unidas em 2006. Dois dados sintetizam os fenômenos mais importantes: 10\% dos adultos do mundo detêm $85 \%$ da riqueza global. Ao mesmo tempo, a metade mais desfavorecida da população mundial fica com menos de $1 \%$ do total (UNU-WIDER, 2006). Os informes de instituições tais como a Organização Mundial da Saúde, o Fundo das Nações Unidas para a Agricultura e Alimentação, a Organização Mundial do Trabalho e, até mesmo a Organização para a Cooperação e o Desenvolvimento, o Fundo Monetário Internacional e o Banco Mundial, divulgados a partir do ano 2000, apresentam dados estarrecedores referentes à fome no mundo, à degradação da qualidade de vida e ao crescimento quantitativo e relativo da pobreza. Apesar do forte crescimento econômico em quase todo o mundo, a OIT sinalizava que, devido à lógica excludente do modelo adotado, os desempregados, em 2006, seriam aproximadamente 900 milhões de indivíduos (22 \% da população ativa). Boletins da ONU indicavam a existência de mais de dois bilhões de indivíduos que vivem na miséria extrema, o que os colocava em situação de vulnerabilidade em face das catástrofes naturais e epidemias e, mais gravemente, da fome. Contrastando com seu habitual comedimento, esses boletins alertavam que um terço da população mundial estava em situação de vulnerabilidade extrema.

Em abril de 2007, ao lançar a edição anual da famosa lista dos bilionários do mundo inteiro, o editor da revista Forbes anunciava que nunca na história da humanidade havia sido produzida tanta riqueza. Segundo Steve Forbes, 2006 fora "o ano mais rico da humanidade", e tudo indicava que 2007 também o seria. De certa maneira, ele tinha razão. Apesar da retração ocorrida após o episódio do World Trade Center em setembro de 2001, a economia mundial estava crescendo num ritmo acelerado. A evolução do Produto Interno Bruto de alguns países batia recordes positivos ano após ano. Considerando-se a produção física, o surgimento de novos inventos, o progresso tecnológico, a descoberta de medicamentos quase milagrosos, a expansão das comunicações e do comércio mundial, além de vários outros indicadores, traduziam um dinamismo produtivo continuado que se alastrava em todo o mundo.

Tamanha prosperidade era interpretada como resultado da adoção dos preceitos neoliberais: redução da presença do estado, desregulamentações, liberalização financeira, fim de barreiras alfandegárias e de controles sobre a movimentação do capital e flexibilização dos contratos de trabalho. $\mathrm{O}$ enfraquecimento dos controles sobre o grande capital favoreceu determinados comportamentos sociais que acentuavam o individualismo possessivo e consumista, fato que forçou a fragmentação dos movimentos sociais clássicos e estimulou a expansão da sociabilidade virtual por meio das novas redes eletrônicas.

Países rivalizavam na divulgação dos índices de crescimento do PIB. China, Chile e Índia cresceram mais do que as velhas potências centrais, embora elas continuassem a registrar expansão superior a 3 ou $4 \%$ ao ano. Obras faraônicas brotavam em países como a Malásia, o Catar ou o México. Um mercado de altíssimo luxo, antes apenas existente em alguns poucos países do Primeiro Mundo, espraiou-se para todos os continentes. A revista Forbes teve de aumentar a escala comparativa da riqueza. Em 2008, para alguém ser considerado verdadeiramente rico nos Estados Unidos, era necessário possuir um bilhão e trezentos milhões de dólares (Forbes, 2008). ${ }^{1}$ Rivalidades en${ }^{1}$ Numa longa, porém discreta nota em pé de página, o editor da revista FORBES indica a metodologia empregada para identificar as grandes fortunas. A equipe de pesquisa entrevistou empregados, concorrentes, consumidores, advogados, ex-esposas e analistas de mercado. Foram considerados balanços contábeis, relatórios de bolsas de valores, enfim, o máximo de informações possível. Mesmo assim, o editor reconhece que a riqueza identificada está subestimada. "Rules of the Road" FORBES, outubro de 2008. 
tre países eram aguçadas pela inclusão de mais ou menos bilionários da lista dos mais ricos do mundo, e a grande mídia se esbaldava em glorificar os representantes "nacionais". Os dois ou três anos que precederam a atual crise correspondem ao ápice de um processo caracterizado por duas noções de difícil enquadramento científico, mas nem por isso menos reveladoras da essência do que estava acontecendo: voracidade (ou ganância) e desmedida (Dilnot, 2008).

David Harvey (1990), com acurada premonição, fez referência à compressão tempo-espaço para caracterizar as transformações que ocorriam instantaneamente nos mais diferentes países. A financeirização e a reestruturação produtiva empreendidas em escala global anulavam as fronteiras e o tempo necessário para ajustes corretivos. Conquistas sociais obtidas após décadas de lutas e direitos coletivos inscritos a duras penas nas constituições eram revertidos por reformas-relâmpago. Processos como fusões entre megaempresas, deslocamentos de fábricas, criação de novas regiões produtivas, que, antes, exigiam anos de negociações e de esforços, passaram a ser realizados em poucos meses. Incontáveis dimensões da vida (e da morte) passaram rapidamente para esfera mercantil. Funções básicas do Estado, tais como segurança, educação e saúde pública e outros serviços de utilidade pública foram transformados em negócios particulares regidos pela lógica do lucro imediato.

O turbo-capitalismo, aquele materializado nas grandes corporações, manifestava uma voracidade sem limites ou, nas palavras de Joen Bakan (2008), era movido pela "busca patológica do lucro e poder". Na ausência de forças contrárias ou corretivas, a apropriação privada da produção social resultou num desmedido processo de concentração de renda. Vários indicadores comprovam essa assertiva, como, por exemplo, o fato de que, em 2005, nos Estados Unidos, a parte recebida pelo $1 \%$ mais rico da população representava mais de $50 \%$ da riqueza nacional. Os outros 50\% eram divididos entre o restante, $99 \%$ da população. Essa desproporção não tinha acontecido desde 1929! No início do século XXI, as 200 pessoas mais ricas do planeta possuíam riqueza substantiva (aquela que gera mais riqueza), equivalente à de dois bilhões e quatrocentos milhões de indivíduos. Essa distribuição indica que apenas um indivíduo possui o mesmo que 12 milhões de pessoas. O relatório anual das Nações Unidas sobre o Desenvolvimento Humano alerta que riqueza pessoal e renda nacional, ou ainda, riqueza líquida e PIB, não são termos comparáveis (ONU, 1996). Apesar disso, o cotejo é válido para indicar, aproximativamente, a desproporção entre o que detêm e recebem alguns poucos indivíduos e a realidade econômica de milhões de pessoas.

Até recentemente, executivos recebiam por ano o que um trabalhador da mesma empresa levaria séculos para acumular. Citando dois casos franceses, os recordes foram batidos por Pierre Veluca (Vallourec), que recebeu, em 2007, o equivalente a 1.192 anos; e por Gerard Mestrellet (Suez) 1.022 anos do salário mínimo vigente na França. Ambos são exemplos de voracidade e desmedida. Enquanto os salários dos trabalhadores foram aumentados em 2,1\% de 2006 para 2007, Mestrellet teve seus ganhos aumentados em 364\% e Veluca em $2.312 \%$ (L'Expansion, 2008). Os casos norteamericanos rivalizam com outros exemplos de desproporção entre os ganhos pessoais e os coletivos, pouco importando se as diferenças são calculadas em termos de salários ou da perequação dos lucros entre acionistas (Reich, 2008, cap.3).

Os gastos de consumo corrente de uma família milionária eram superiores às despesas com alimentação de um bairro com centenas de famílias. A comparação, nesse caso, não precisa ser feita entre um milionário norte-americano e moradores de uma favela no Senegal ou de um pueblito boliviano, mas, sim, entre esse mesmo milionário e os trabalhadores que moram nas favelas de Chicago.

A possibilidade de as fortunas de magnatas serem multiplicadas em poucos anos não ocorre apenas em regimes ditatoriais do Terceiro Mundo. Em 15 anos, de 1987 a 2002, a parte apropriada por apenas $0,1 \%$ dos norte-americanos dobrou, alcançando quase $10 \%$ da renda nacional (Tabb, 2006), e, nos cinco anos seguintes, dobrou nova- 
mente (Roux, 2008). Essa situação levou o mega investidor Warren Buffett a declarar em 2006: "Está acontecendo a guerra de classes, mas é minha classe, a classe rica, que está fazendo a guerra, e nos estamos ganhando"2 (New York Times, 2006).

As distâncias sociais e econômicas, que tinham sido reduzidas em muitos países graças ao Welfare State, voltaram a ser ampliadas a tal ponto, que as agências internacionais começaram a fazer referência a elas sem meias palavras e alertando que as desigualdades crescentes constituíam um risco para a democracia e também para o bom funcionamento da economia (Poverty; Focus, 2007; World Bank, 2006).

Esse quadro macroeconômico e macrossocial permite inúmeras análises de interesse sociológico. Poder-se-ia considerar como foram modificadas as relações sociais de produção que permitiram a fragmentação da classe operária; como prosperaram os valores e os comportamentos individualistas; como são construídas as novas redes sociais do poder que envolvem a representação parlamentar, o controle da mídia e a corrupção do poder executivo. O tema das estratégias de produção e reprodução ampliadas das desigualdades diz respeito a questões essenciais como é o caso das populações vulneráveis, das novas discriminações de gênero e raça e, nos casos extremos, do que Alberto Bialakowsky (2007) chama de "populações extinguíveis". Dizem respeito, também, aos movimentos de resistência e à construção das alternativas políticas e econômicas.

Porém, considerando que não existem segmentos estanques quando o tema envolve desigualdades socioeconômicas, que o polo riqueza e o polo pobreza ou os segmentos intermediários mantêm necessárias e indissolúveis relações, a análise dos indivíduos que estão no topo da pirâmide social e que são detentores de imensas fortunas se apresenta como imprescindível. Frequentemente, o tema da composição social remete apenas aos segmentos mais pobres e, em alguns casos, àqueles identificados com grande imprecisão como com-

2 “There's class warfare, but it's my class, the rich class, that's making war, and we're winning." ponentes da classe média. Por razões objetivas, milionários e bilionários raramente são estudados pela Sociologia (Pinçon; Pinçon-Charlot, 2007), embora eles estejam no epicentro da crise econômica mundial. Seus interesses, seus comportamentos sociais e suas ações políticas afetam, de maneira decisiva, o conjunto da sociedade, seja ela norte-americana, inglesa, colombiana, tailandesa, brasileira ou qualquer outra.

Depois da eclosão da crise econômica em outubro de 2008, a grande mídia registrou com destaque a diminuição do poderio desse grupo. Segundo o noticiário, algumas fortunas teriam sido reduzidas à metade. Essa informação não diminui a importância do fenômeno e, em alguns casos, serve para deslocar o foco das atenções, garantindo sigilo sobre o real processo em curso como maneira de preservar o poder e os privilégios dos segmentos mais abastados. A redução das atividades para um pequeno empresário, ou empresário por conta própria, ou ainda a perda do emprego para os assalariados, produzem efeitos imediatos: redução da qualidade de vida, não acesso ao crédito, sofrimento psíquico, ampliação da vulnerabilidade e intensificação da deriva social (Cattani, 2000). Perdas individuais podem atingir também as altas fortunas, porém com consequências que não têm o mesmo significado daquelas que afetam aposentados, trabalhadores ou pequenos e médios empresários. Um exemplo particularmente ilustrativo aparece no comportamento de um grande investidor brasileiro. Em meados de outubro de 2008, quando registrava perdas de US\$ 600 milhões nos seus investimentos, Lírio Parisotto viajou a França para adquirir uma partida especial do vinho Romanée-Conti, dizendo-se pouco preocupado, pois recuperaria tudo em pouco tempo (Lima, 2008).

\section{HNWIS - UM SEGMENTO DOS SETORES DOMINANTES}

Hight Net Worth Individuals (HNWIs) designa indivíduos com capacidade de reprodução econômica e social assegurada pela posse de gran- 
des fortunas. Eles podem ser denominados simplesmente ricos, milionários ou bilionários. A sigla HNWIs, porém, remete para significados contemporâneos objetivos: alude à existência de segmentos específicos das classes dominantes em escala internacional, não mais vinculados a territórios nacionais; traduz a apropriação personificada da riqueza; revela a existência de circuitos seletivos de consumo que contrastam, de maneira abissal, com os padrões de vida do restante da população.

Para um recorte mais preciso desse segmento, é necessário explicitar, primeiramente, ao que ele não corresponde. Caudatários da obra de C. Wright Mills (1956), de Ferdinand Lundberg (1969) e de Willian Domhoff (1983), economistas, sociólogos e cientistas políticos buscaram identificar os detentores do poder sob perspectivas mais abrangentes. Enquanto os três autores norte-americanos tiveram os Estados Unidos como foco exclusivo da análise, a globalização, tendo se tornado o fato econômico mais relevante do final do século XX, levou os demais pesquisadores a analisarem a existência de uma "elite global", ou de um grupo de indivíduos poderosos que constituiriam uma "classe mundial". De um modo geral, essas tentativas, que têm o favor da mídia (ver, por exemplo Newsweek, 2008), acabam produzindo resultados inconsistentes ou equivocados. Uma definição abrangente de elite considera personalidades com perfis, atributos e poderes muito distintos, tais como presidentes (provisórios) de Bancos Centrais, Chief Executive Officers (CEO) de multinacionais, cientistas, sheiks árabes, intelectuais e artistas. Ben Bernanke pode figurar na lista junto com Bill Gates, Silvio Berlusconi, Bono Vox, Dalai Lama e... Paulo Coelho. Classe pressupõe identidade, unidade, coesão, atributos e existência coletiva com base em circunstâncias e situações relativamente homogêneas e, por fim, capacidade de mobilização com vistas aos interesses comuns.

Porém a tentativa de identificação de uma superclasse leva à criação de listas mais focadas em indivíduos articulados em instâncias tais como a Comissão Trilateral, o grupo de Davos, o grupo de Bilderberg ou a Mont Pelerin Society. A men- ção implícita ou, por vezes, explicita, a grupos extremamente pequenos se associa rapidamente a delirantes teorias da conspiração (Rothkopf, 2008, cap.8). A existência de pequenos grupos secretos, que visam a controlar o mundo, faz parte das lendas contemporâneas que captam fragmentos da realidade, tentando explicar os acontecimentos de maneira esotérica.

Sem desconhecer o fato de que representantes de poderosos grupos da mídia e de megacorporações industriais têm elevada capacidade de moldar o sistema mundial, o mapeamento de uma classe poderosa unida e articulada é um esforço por vezes infrutífero. De estudos pretensamente científicos de Pareto ([1916] 1988) às banalidades jornalísticas de Rothkopf (2008), a referência a uma hipotética "elite mundial" só pode resultar em generalidades desconexas que, tomando como base a História, acabam propugnando a necessidade e a inevitabilidade da concentração do poder.

Outros trabalhos tentam analisar com fundamentos científicos mais consistentes a constituição de uma classe capitalista transnacional. Por exemplo, Anne-Marie Wagner (2007) destaca que, embora não seja um fenômeno novo, a globalização proporcionou o surgimento de grupos cosmopolitas com formação, entrosamento e circulação distintos da velha burguesia ancorada nos seus países de origem. Leslie Sklair (2001) identifica proprietários e controladores das megacorporações, dividindo-os em quatro frações: a corporativa, composta por altos executivos; a estatal, da qual fazem parte burocratas e políticos; a fração técnica, formada por profissionais globalizantes; e a quarta chamada de "consumerista", constituída por comerciantes e pela mídia. O objetivo do autor é demonstrar que a relação entre propriedade e controle não se limita aos meios de produção, exigindo uma articulação com as esferas política, organizacional, cultural e intelectual. Essa e outras análises permanecem ainda num nível muito elevado de abrangência, carecendo de refinamentos empíricos e teóricos capazes de explicar problemáticas específicas, relações entre o global e o local e, especialmente, que possam identificar manifestações objetivas das estratégias 
de reprodução dos setores abastados e das formas de dominação.

O recorte proposto que identifica os HNWIs busca colaborar nesse sentido, pondo em evidência aspectos relevantes de segmentos das classes abastadas, com projeção e circulação internacionais, detentores de fortunas expressivas cuja mobilidade é assegurada pelo acesso a nichos e circuitos particulares da economia globalizada. Critério decisivo para a circunscrição desse grupo é que suas fortunas estejam relacionadas a atividades produtivas ou financeiras, envolvendo extração ou apropriação do valor e exploração da força de trabalho. O espaço de realização desse processo é constituído pela economia institucionalizada em moldes capitalistas, desconsiderando os indivíduos abastados cuja riqueza provenha de atividades artísticas, esportivas, intelectuais e, menos ainda, indivíduos cujas fortunas decorram de atividades criminosas.

O núcleo decisivo dos super-ricos não é composto por indivíduos cujas fortunas dependeram do trabalho ou do talento. A riqueza está associada essencialmente ao capital.É ele que definirá as posições na estrutura social, o prestígio, o reconhecimento e, sobretudo, as condições e modalidades de exercício do poder (Haseler, 2000).

A sigla HNWIs não corresponde à idéia de uma classe social que se assemelhe à plutocracia, pressupondo identidade, coesão e mobilização coletiva a partir de interesses homogêneos e articulados. Ela tampouco se aplica ao sentido corrente de elite, compreendida como composta por indivíduos socialmente superiores, cuja riqueza é proveniente do talento ou da capacidade operativa. A expressão high net worth individuals não é um conceito das Ciências Sociais, pois ela foi forjada e aplicada por importantes instituições financeiras internacionais para se referirem a indivíduos ou famílias, ou seja, não a empresas ou corporações que dispõem de recursos líquidos para investimentos (investable assets) superiores a um milhão de dólares. Eles seriam aproximadamente nove milhões em todo o mundo e 95 mil no Brasil. Com grau maior de precisão, as instituições designam os Ultra High
Net Worth Individuals representados por menos de cem mil indivíduos ou famílias; para ser classificado como ultra, é necessário possuir mais de US\$ 30 milhões líquidos (Capgemini, 2006).

A utilização da sigla HNWIs neste artigo, como sinônimo de super-ricos, leva em consideração o fato que ela corresponde a um fenômeno social e econômico identificado primeiramente por grandes bancos e corretoras. Ou seja, não se trata de um constructo acadêmico, e sim de uma realidade objetiva, cuja existência impacta fortemente o restante da sociedade e, por isso, precisa ser analisada pelas Ciências Sociais. Os argumentos utilizados por Stephen Haseler (2000) nos parecem corretos. Como Wright Mills, Ferdinand Lundberg e William Domhoff (2006), Haseler insiste na questão da escala como elemento decisivo. Não é possível ignorar que a riqueza possuída por alguns poucos indivíduos é maior do que a soma dos recursos de dezenas de países; que iniciativas tomadas por apenas um mega-investidor afeta milhões de trabalhadores, ou ainda que, pelos efeitos de poder, esse mesmo especulador esteja acima da lei e dos deveres cívicos elementares.

Os HNWIs se caracterizam por três aspectos principais: a) desvinculação de dimensões físicas do capital e de amarras nacionais; b) personificação das fortunas; e c) faustuoso padrão de vida.

Quanto à desvinculação de dimensões físicas do capital e de amarras nacionais, constata-se que suas fortunas independem de uma vinculação física com um setor produtivo específico que, até o passado recente, tinha laços fortes com um determinado território. De modo geral, a parte substantiva dos seus rendimentos está associada ao capital volátil, aquele que circula eletronicamente no mundo inteiro, passando por bolsas de valores e de mercadorias, pelo mercado de câmbio e de títulos públicos, materializando-se ao sabor dos ganhos imediatos em commodities, empresas produtivas, imóveis, dentre outros. Mazlish e Morris (2005, p.170) registram depoimentos de executivos de grandes conglomerados que se consideram cidadãos do mundo. Acima de leis nacionais, distantes de qualquer reconhecimento ou respeito à 
origem local da riqueza, eles regem seus patrimônios buscando a rentabilidade máxima no curto prazo.

Um exemplo dessas estratégias supranacionais é dado pelo caso argentino. Nenhum critério patriótico impediu a fuga de capitais às vésperas da grande crise de convertibilidade. $\mathrm{O}$ mais estrito oportunismo intensificou as consequências desastrosas para a economia desse país (Gaggero, 2007). Ao constatarem perdas massivas de empregos, devido ao deslocamento de plantas industriais para a China, sindicatos alemães, ingleses, franceses e canadenses fizeram apelos nacionalistas tentando, sem sucesso, reverter o processo de relocalização. Exortações patrióticas lançadas pelo governo norte-americano após os atentados de 11 de setembro e durante o auge da crise financeira também fracassaram em face do "internacionalismo" militante dos executivos das grandes corporações. Caso revelador é o que ocorreu na gestão de Carly Fiorina - CEO da Hewlett Packard, eleita executiva do ano 2004 pela revista Fortune. Contra todas as recomendações do governo Bush, a HP negociava abertamente com iranianos. Como ela, executivos com capacidade de agenciar recursos milionários tornaram-se tão poderosos e imunes a controles, que o slogan anarquista "sem pátria e sem patrão" a eles se aplica. Emblemáticas empresas norte-americanas como John Deere (máquinas agrícolas), WalMart (supermercados) e Timberland (calçados e têxteis) podem manter sedes de fachada nos seus países de origem, embora, para aproveitar isenções e benefícios fiscais, as sedes oficiais estejam situadas no Cantão de Schaffhausen (Suíça) ou na Isle of Man ou em Luxemburgo. Com maior agilidade, os proprietários e altos executivos seguem o mesmo caminho.

O desprendimento do torrão natal é pautado por razões pragmáticas. Em alguns casos, corresponde a estratégias que visam a assegurar a impunidade em casos de condutas ilícitas. Em outros, atende a um utilitarismo econômico extremado. Seguindo o exemplo de Mônaco e de algumas ilhas do Caribe, ao reduzirem substancialmente os impostos sobre altas fortunas, cidades como Londres e Marrakech atraíram levas de bilionários do mundo inteiro que não sentiram saudades de suas mansões para viver como príncipes em La Palmeraie ou como lordes em Chelsea. Entre eles, três brasileiros, um dos donos da AMBEV, o dono da Natura e uma das principais acionistas do Banco Safra. A desterritorialização também é facilitada pela utilização dos paraísos fiscais que permitem a circulação e a multiplicação do capital, feitas de todas as maneiras possíveis. Em face do internacionalismo sem fronteiras dos super-ricos, Stephen Haseler (2000, p.23) lembra o aforismo de George Orwell: "Os pobres são os únicos verdadeiros patriotas".

A personificação da riqueza é uma dimensão essencial para identificar práticas que caracterizam os HNWIs. Por personificação entende-se o processo de apropriação e de fruição da riqueza por uma pessoa, independentemente das leis da acumulação. Lucros em volumes crescentes deixam de ser reinvestidos no processo produtivo e são transferidos para a esfera privada (Cattani, 2007, p.84-86).

Dados disponíveis nos Estados Unidos provam que, entre 1990 e 2005, os lucros corporativos aumentaram $106 \%$ e que os rendimentos auferidos pelos executivos das grandes corporações aumentaram 298\% no mesmo período (Domhoff, 2006). Esse extraordinário processo de transferência de renda deve-se à capacidade de mobilização econômica e política, que permitiu, entre outros aspectos, a redução de impostos sobre os rendimentos pessoais dos detentores de altas fortunas. Enquanto a carga tributária permanecia a mesma ou até aumentava sobre os resultados dos setores produtivos, diminuía a taxação sobre ganhos pessoais e a transmissão do patrimônio.

Outro aspecto relevante diz respeito ao fato de que alguns executivos tornaram-se figuras públicas com grande legitimidade junto à opinião pública e aos investidores, sendo mais conhecidos do que as empresas por eles administradas. Eles se destacaram pelos resultados obtidos em termos de retorno de investimentos, mesmo que isso custasse a perda de empregos, o esvaziamento de regiões produtivas e o próprio sucateamento 
das empresas. Há mais de 10 anos, Loïc Wacquant analisava como os patrons-décepeurs (executivosaçougueiros), estavam sendo glorificados como heróis no mundo dos negócios. (Wacquant, 1996). Livros de administração de empresas usavam a expressão pit bull managers que, longe de representar uma crítica ao caráter obsessivo, cruel, impiedoso e predatório das práticas gerenciais, vangloriava a audácia dos executivos responsáveis pela degradação das condições de trabalho e pela redução de salários de milhares de trabalhadores. Executivos com comportamentos mais próximos aos de capos mafiosos apareceram na imprensa econômica especializada como audazes construtores da alta modernidade empresarial. Práticas econômicas nefastas ao interesse coletivo ou iniciativas predatórias contra o meio ambiente foram aceitas como exemplos de racionalidade e eficiência provenientes de cérebros privilegiados.

Alguns casos chamam a atenção, como o de Donald Trump, midiático empresário norte-americano da construção civil, dono de cassinos e promotor televisivo da cultura empresarial baseada em graus extremados de concorrência. Louvado como resultado de uma seleção de competências no mercado, seu sucesso esconde estratégias fraudulentas e um intrincado esquema de influência e corrupção. É também o caso dos executivos de aluguel, tais como Al Dunlap e Thomas Labracque, apresentados como gênios empresariais por gerarem rendimentos imediatos para os acionistas (shareholder value), a despeito das graves consequências sociais e econômicas das suas estratégias. As modificações introduzidas nas empresas resultaram em ganhos fulgentes, não repetidos posteriormente. Em alguns casos, as medidas fragilizaram as empresas, levando-as quase à insolvência, sem que isso tenha afetado as finanças pessoais dos responsáveis, uma vez que os recursos já tinham sido transferidos para portos seguros. A crise financeira de 2008 está repleta de situações análogas. Executivos de grandes bancos que registraram perdas expressivas, ou mesmo que foram à falência, tinham sido contemplados com rendimentos milionários poucos meses ou dias antes da eclosão da crise.

A personificação da riqueza pode ser revelada pela prática de obtenção dos chamados golden parachutes. ${ }^{3}$ A partir de 1990, o poder de alguns administradores à testa de grandes corporações cresceu de tal modo, que eles conseguiram aprovar benefícios pessoais desmedidos, isto é, nãoassociados à rentabilidade efetiva das empresas. Executivos afastados do comando dos negócios receberam valores maiores que os ganhos corporativos e, estranhamente, em recursos monetários não-associados a stock options da própria empresa. Um caso entre tantos outros é o de Gilbert Mittler, alto executivo do Banco Fortis. Apesar da falência da empresa, ele teria recebido um bônus de quatro milhões de euros e sido contratado como "conselheiro especial”. Mittler, Jean-Paul Votron e Maurice Lippens, os dois últimos ex-diretor e expresidente, foram responsáveis por operações que levaram o banco à bancarrota (Le Monde, 2008). Um caso simbólico é o de Richard Full, durante muito tempo elogiado pelo seu comportamento agressivo, que lhe valeu o apelido de Wall Street Gorilla. Full recebeu mais de quinhentos milhões de dólares antes de ser considerado o principal responsável pela quebra do Lehman Brothers.

A incapacidade de controle internacional sobre as corporações e a aceleração do processo especulativo dos traders com commodities abriram possibilidades de apropriação individual de ganhos (Godechot, 2007). Fortunas incalculáveis foram amealhadas em pouco tempo. Os ganhos advindos da crise dos alimentos em 2007, da especulação em torno do preço do barril de petróleo em 2006 e 2007, e, especialmente da bolsa de valores até maio de 2008, não serviram para reforçar o caixa das empresas, ocorrendo, no mundo todo, uma transferência para determinados indivíduos. Os balanços e informes empresariais publicados desde o início da crise registram perdas substantivas, porém, indicadores indiretos apontam para a ampliação da renda e do patrimônio pessoais.

${ }^{3}$ Prêmios e indenizações concedidos a certos executivos proeminentes por ocasião da sua aposentadoria ou abandono do cargo. 
Uma minuciosa análise dos balanços financeiros de 120 grandes empresas norte-americanas cotadas em bolsa revela que os principais executivos e membros de direção embolsaram mais de 21 bilhões de dólares entre 2002 e 2007 (The Wall Street Journal, 2008). Algumas dessas empresas passaram por situações de insolvência, enquanto seus administradores transferiam recursos para contas particulares, garantindo a preservação e a ampliação do seu patrimônio pessoal.

Um dos casos mais expressivos envolveu o Barclays Bank, segundo maior banco privado do Reino Unido. Em meados de outubro de 2008, no auge da crise econômica, o pacote de medidas organizadas pelo governo britânico previa a injeção de recursos públicos no Royal Bank of Scotland, no Lloyds e no Barclays para salvá-los de uma provável bancarrota. Os executivos do Barclays preferiram transferir parte do controle acionário para financistas árabes e não para o governo inglês. A explicação é muito simples. Com o aumento da participação governamental no controle do banco, os dividendos e bônus pagos aos executivos seriam limitados (Guardian, 2008). A ganância inverteu o ditado popular: "Vão-se os dedos (os bancos), mas ficam os anéis".

A história econômica do Terceiro Mundo é repleta de casos de ditadores e empresários que saqueavam os recursos nacionais para depois fixarem residência em Paris ou Mônaco, assegurando impunidade e fruição da riqueza. Menos conhecidas são as fraudes que sempre ocorreram nos países economicamente avançados e que, agora com a crise, alcançaram relativa visibilidade. Meses antes e, em alguns casos, no auge da crise, executivos do Royal Bank of Scotland (Reino Unido) posteriormente nacionalizado - se apropriaram de centenas de milhões de libras ou euros, o que concorreu para debilitar ainda mais o banco. Poderse-ia dizer que se trata de indivíduos afortunados, que estão além do capital...

Pelos efeitos de poder, a tributação que recai sobre os detentores de altas fortunas é proporcionalmente menor do que aquela sobre o restante da população. Em muitos países, os lucros obti- dos nas aplicações da bolsa de valores não são tributados, enquanto o imposto de renda incide sobre salários ou rendimentos muito baixos. Além disso, graças a intrincados mecanismos, os verdadeiramente ricos conseguem se subtrair às obrigações cívicas elementares, tais como impostos e taxas que recaem sobre qualquer contribuinte de menor porte. A extrema mobilidade permitida pela ausência de controles públicos permite que eles transfiram valores líquidos e propriedades de um país para outro, evitando, igualmente, qualquer contribuição social.

A lei inexorável da acumulação imposta pelas lutas em torno da apropriação do excedente obriga o reinvestimento constante para assegurar a reprodução do capital. Como a própria crise revelou, os saques pessoais sobre o investimento produtivo não podem perdurar por muito tempo. Mas, enquanto foi possível, a "canibalização" dos recursos permitiu aos HWNIs amealharem fortunas consideráveis que garantiram impunidade, reforço das situações de poder e fruição pessoal a expensas do capital e dos trabalhadores.

Os casos citados, alguns poucos entre milhares, revelam as condições políticas, ideológicas e sociais vigentes no final do século XX e início do século XXI-especialmente o enfraquecimento das forças sociais do trabalho e dos sistemas de controle estatal - que permitiram a ocorrência desses fatos (Reich, 2008, p. 80 e sequência). Eles demonstram que, nessas circunstâncias especiais, "estar além do capital" não é uma exagerada e inconsistente expressão retórica, mas a tradução de fatos concretos que envolvem estratégias de apropriação privada (no sentido de individualizada) da riqueza, em detrimento das próprias empresas e, em especial, do interesse coletivo.

O consumo fausto ou o consumo aristocrático foram objetos de importantes estudos sociológicos. Thorstein Veblen (1983) entendia o consumo conspícuo como uma estratégia de distinção entre classes dominantes concorrentes. Pierre Bourdieu no clássico A distinção (2007), define o consumo ostentatório no campo das lutas de classes claramente identificadas: setores populares 
dominados versus burguesia dominante ou em vias de sê-lo. Para esse autor, as lutas pela classificação como grupo superior estão diretamente vinculadas ao campo político. A estilização da vida em moldes e termos elitistas visa a assegurar a legitimidade da dominação.

As reflexões de Veblen se basearam na realidade norte-americana do final do século XIX, marcada pela luta entre segmentos das classes proprietárias, constituídos de um lado, por latifundiários e aristocratas que usufruíam de rendas não originadas do trabalho e, de outro, por representantes de um capitalismo industrial operoso. Para Veblen, as despesas suntuosas e a ostentação exagerada eram próprias dos setores rentistas tradicionais, considerados por ele uma classe ociosa e parasitária em vias de extinção. Suas análises, em termos de consumo conspícuo, não se aplicam às "classes de fruição" contemporâneas, ligadas aos setores modernos e dinâmicos. Por sua vez, Bourdieu se referia à situação francesa de meados dos anos 1970, ou seja, antes do extraordinário desenvolvimento de um mercado de altíssimo luxo, ocorrido depois de 1985, cujas dimensões não se limitam à aquisição de capital cultural como forma de distinção pela excelência e sofisticação.

O consumo faustoso dos HNWIs apresenta desdobramentos mais complexos, associados às características desse grupo, tais como foram resumidas anteriormente. Desterritorializados e descompromissados com a sobrevivência, no longo prazo, de esferas produtivas específicas, os segmentos abastados usufruem de um mundo à parte, exclusivo e onírico, destinado ao aproveitamento imediato e intenso da riqueza. De posse da riqueza em escala desmedida, eles podem esterilizar recursos das formas mais inusitadas. Um número especial da revista Newsweek (2007) registra os casos extremos, indicando como os verdadeiramente ricos estavam se separando os "meros milionários”. Bens, espaços e serviços únicos, por vezes discretos, por vezes ostentatórios, permitem a fruição da riqueza extraída da esfera produtiva sem que ela esteja necessariamente relacionada à busca de legitimidade, reconhecimento ou, nas palavras de Bourdieu, de classificação perante o restante da sociedade. Os exemplos proliferam, oscilando entre o ridículo e o escandaloso, o esterilizante e o claramente criminoso: sutiã cravejado de diamantes (US\$6 milhões), celulares, idem (US\$2 milhões), estadia em hotéis temáticos na selva ou no deserto (US\$ 10 mil a diária), viagens particulares ao espaço (US\$35 milhões por passageiro); bespoke design (valores diversos na casa de milhares de dólares); iguarias estranhas que incluem ouro em pó ou animais em extinção; compra de ilhas privadas (de US\$ 10 milhões a US\$100 milhões); idem, jatos e iates (de 10 a 130 milhões); mansões em Palm Beach, Aspen ou no Chelsea (acima de 200 milhões). O recorde continua sendo a compra da mansão de Lilly Safra na Côte d'Azur: 500 milhões de euros (Frank, 2007; Newsweek 2007, 2008; Sciences Humaines, 2008).

O crescimento extraordinário do consumo de alto luxo fez com que os principais jornais e revistas de grande circulação criassem seções especializadas para divulgar produtos e serviços destinados aos milionários, no que foram copiadas por publicações e sites com os mesmos objetivos (www.webluxo.com.br; www.riquissimos.com.br; www.privateislandsonline.com) Em certos momentos o esbanjamento chega ao paroxismo, como no caso de uma loja brasileira de alto luxo que lançou um modelo popular de sandálias de plástico, bordadas com penas de ouro e diamantes, vendido na época ao valor unitário de 58 mil reais (Carta Capital, 2003). As clientes que adquiriram o produto, usando-o uma única vez por algumas poucas horas, gastaram o equivalente ao que um trabalhador remunerado pelo salário mínimo recebe em 17 anos!

Mesmo que a prodigalidade sem limites seja acintosa, não cabe nenhuma apreciação de caráter moralista sobre a natureza do consumo. Os gastos faustuosos devem ser considerados como indicativos dos volumes extraordinários apropriados por alguns poucos HNWIs que acabam esterilizando-os porque não encontram mais espaço de realização na esfera produtiva. Nos últimos 25 anos, a "internacional dos ricos" (Manière de Voir, 
2008) realizou um saque planetário em detrimento de milhões de trabalhadores. A apropriação privada do valor produzido socialmente ocorreu em termos tão desequilibrados, que provocou uma crise de subconsumo numa época de superabundância de riqueza.

Existe outro aspecto ideológico associado a essa transferência desmedida de renda, que merece ser destacado. A vida privilegiada de algumas personalidades é vista como merecida recompensa; suas realizações econômicas são invariavelmente compreendidas como legítimas, o que lhes assegura privilégios e impunidade em detrimento de interesses nacionais e do bem comum. Depois de outubro de 2008, ocorreram algumas reações violentas dirigidas contra altos executivos. Porém, à exceção dos casos de retenção de empresários por sindicalistas na França, nos demais países do Primeiro Mundo, as manifestações foram realizadas por pequenos acionistas lesados pela crise. Não há registro de nenhum dos dois casos no Terceiro Mundo.

De maneira geral, os HNWIs continuam aparecendo no topo da estratificação social, noápice da pirâmide que representa as diferentes classes. Esse lugar é ocupado de maneira inquestionável, sem contestação por parte da maioria das pessoas. Poder e privilégios não são entendidos como associados a mecanismos objetivos de transferência de renda de muitos para poucos. Essa dimensão indica como os detentores do poder econômico conseguem manipular a opinião pública, desviando o foco das atenções apenas para o lado mundano, fútil ou charmoso dos extremamente ricos.

No pensamento dominante, o processo de apropriação privada da riqueza aparece glorificado como resultado positivo e eficiente dos comportamentos humanos regidos pelo empreendedorismo na esfera do mercado pretensamente autorregulável. Prestígio, luxo e regalias seriam provenientes da justa e eficiente remuneração dos esforços despendidos pelos agentes talentosos. Em tais percepções, o senso comum acompanha as concepções elitistas, justificando hierarquias e privilégios: a pobreza seria culpa do pobre, a riqueza, mérito do rico.

\section{QUANTO MAIS OS POBRES APARECEM MENOS OS RICOS SÃO VISÍVEIS}

A temática das classes abastadas com suas inúmeras e complexas dimensões de importância sociológica não é desenvolvida por dificuldades objetivas de acesso ao mundo restrito, protegido e, aparentemente, à parte daqueles que estão no topo da pirâmide social. A imagem da pirâmide, muito utilizada para representar a estratificação social, indica a distância que existe entre os poucos que estão em cima e os muitos que estão embaixo. Frequentemente, porém, o ápice da pirâmide é entendido como descolado da larga base, como se os que compõem o topo flutuassem no espaço, sem manter relações sociais de dominação e de exploração sobre o restante. Oportuna, essa imagem de mundos desvinculados é construída a partir duas estratégias.

A primeira é o bloqueio à investigação. Como afirma Marcelo Medeiros (2005): “os ricos se escondem". Acreditando que o estudo sobre sua situação possa se traduzir em medidas que as beneficiem, as populações pobres são extremamente permeáveis às pesquisas, deixando-se facilmente auscultar, inventariar e descrever. Não existem aspectos que não sejam desvelados ao olhar do sociólogo, do assistente social ou dos entrevistadores de órgãos estatísticos. Tal apuração não ocorre com o segmento mais rico, que não tem interesse algum que seu patrimônio, sua renda e seus comportamentos venham a público. No caso brasileiro, a obrigação legal de fornecer informações ao Instituto Nacional de Geografia e Estatística (IBGE) é descumprida sistematicamente pela classe alta. Os técnicos são obrigados a retornar várias vezes às residências, sem garantia de serem recebidos e, sobretudo, sem poderem assegurar minimamente a veracidade das informações.

A boutade de Marx, no prólogo de O Capital, de que, na porta de cada fábrica, existe uma placa indicando "No admittance except for business", pode ser adaptada para o mundo das grandes fortunas: "No admittance except for making money". Qualquer investigação por parte das autoridades 
governamentais e, em maior medida, qualquer estudo científico encontrarão incontáveis barreiras criadas por advogados e especialistas em administração de grandes fortunas ou, simplesmente, obstáculos físicos guardados por seguranças armados. Se o pesquisador não for dissuadido a abandonar sua enquete pelos porta-vozes dos milionários a serem estudados, a ameaça de processos judiciais ou os argumentos físicos o farão.

Os detentores das altas fortunas têm interesse em preservar controle absoluto sobre os aspectos que lhes interessam divulgar, mantendo sigilo total sobre as fontes de rendimentos e dando, eventualmente, visibilidade aos aspectos da vida social que ratificam seu prestígio.

Outra estratégia ou ordem de impedimentos à pesquisa diz respeito aos limites da própria Ciência Social. Ricos e poderosos aparecem na dupla dimensão de totem e tabu. De um lado, seres envoltos em mistério, com os quais existe uma relação de veneração e de temor; de outro, seres cujo acesso é desconsiderado por insuficiências teóricas e metodológicas.

Como bem analisaram Michel Pinçon e Monique Pinçon-Charlot (2007), a temática da riqueza sofre uma série de preconceitos associados à aparente falta de legitimidade política do tema. $\mathrm{O}$ estudo dos pobres e miseráveis é considerado prioritário em vários campos do conhecimento e para a definição de políticas de Estado. De um modo geral, estudar os que estão na base da pirâmide social é entendido como parte indispensável da estratégia de combate à pobreza, ou para o empoderamento dos sujeitos, visando a reduzir as desigualdades mais gritantes. Esse argumento desdobra-se no seguinte raciocínio: estudar os pobres é se interessar pela causa dos pobres. Por paralelismo, estudar os ricos é se identificar com a causa dos ricos. Ou, também, estudar elites econômicas é ser elitista.

Esse raciocínio é reforçado na distribuição de verbas públicas destinadas à pesquisa. Confrontados dois projetos concorrentes - um que visa a, hipoteticamente, estudar "Estratégias de sobrevivência da população pobre da favela X”; e outro que busca analisar "Sociabilidade e padrões de consumo no condomínio fechado de alto luxo Y" - a tendência será priorizar aquele que, aparentemente, tem uma função social. É bem provável que o segundo seja considerado um tema fútil, não merecedor de apoio governamental. A produção de conhecimento, no primeiro caso, pode ser indispensável para uma correta avaliação das políticas que auxiliem os envolvidos a saírem da situação de pobreza. Mas, a segunda proposta pode trazer elementos explicativos do contínuo e renovado processo de produção de pobreza. No caso específico, parte dos moradores condomínio Y é composta pelos mesmos empresários que, durante os jogos de golfe, socializam as estratégias de guerrilha trabalhista para explorar os trabalhadores da favela X. Nas reunióes sociais, suas esposas elaboram listas negras para excluírem serventes e faxineiras que contestam o preço vil pago para limpar e cuidar das mansões. Além disso, a implantação do condomínio em área de preservação ambiental foi possível com a corrupção de funcionários públicos. Enquanto os favelados pagam impostos urbanos e sofrem com a falta de saneamento básico e de transporte decente, os moradores do condomínio de luxo gozam de isenção tributária e tiveram as suas vias de acesso asfaltadas pela prefeitura.

Pinçon e Pinçon-Charlot (2007) identificam outras barreiras criadas pela incapacidade de os cientistas sociais superarem sua timidez em face dos poderosos.

Trabalhando em meios populares ou médios, o sociólogo goza de uma relação desequilibrada a seu favor. Nessa situação de pesquisa, encontrase em posicão dominante [...]. Mas é diferente quando se trata de enfrentar na entrevista ou no trabalho de campo, agentes providos de mais capital sob todas suas formas [...]. Um grande burguês sempre sabe se manter no seu lugar e colocar o sociólogo no seu, eventualmente com uma polidez refinada, arma temível da dominação de classe. (2007, p.24)

Embora complexa e sempre dificultada por razões objetivas e ideológicas, a análise aprofundada dos indivíduos situados no topo da estratificação socioeconômica apresenta as seguintes possibili- 
dades: a) pensar a estrutura social como um todo integrado e articulado, o polo pobreza como nãodissociado do polo riqueza; considerando-se as dimensões relacionais entre ambos, é possível desvelar os reais processos de apropriação e de transferência de renda; b) questionar as posições econômicas e sociais privilegiadas, ponderando em que medida elas resultam de processos meritocráticos ou se são frutos de estratégias de dominação econômica, ideológica e social; c) desenvolver a crítica sobre a pretensa racionalidade dos processos econômicos contemporâneos, marcados por diferenças de escala que definem privilégios, força e poder para uma minoria. Essa última questão remete a um ponto pouco explorado. O capital não é uma abstração, ele não está diluído no espaço indiferenciado das empresas. HNWIs são a encarnação identificável de parte dos agentes que comandam o processo de exploração do trabalho e os processos políticos que permitem a extração do valor.

A apreensão dessas dimensões pode contribuir para o conhecimento dos processos sociais que permitem contra-atacar a apropriação privada desmedida da riqueza socialmente produzida, reduzindo, assim, as desigualdades socioeconômicas mais graves.

(Recebido para publicação em maio de 2009) (Aceito em agosto de 2009)

\section{REFERÊNCIAS}

BAKAN, J. A corporação. São Paulo: Ed. Novo Conceito, 2008.

BIALAKOWSKY, A. Práticas governamentais na regulamentação de populações extinguíveis. In: CATTANI, A; CIMADAMORE, A. (Org.) Produção de pobreza e desigualdade na América Latina. Porto Alegre: Tomo Editorial; Buenos Aires: Clacso, 2007. p.151-194.

BOURDIEU, P. A distinção. Critica social do julgamento. Porto Alegre: Zouk; São Paulo: Edusp, 2007.

CAPGEMINI. World Wealth Report. Nova York: 2006.

CARTA CAPITAL. Da cabeça aos pés. São Paulo, n.269, p.24-28, 03 dez., 2003.

CATTANI, A. D. Desemprego e degradação social. TrabaIho e autonomia. Petrópolis: Vozes, 2000. Cap.2.

DILNOT, C. The triumph of greed. Newstatesman, Londres, 08 dec., 2008
DOMHOFF, W. Who rules America? Nova York: Simon \& Schuster, [1983] 2006.

FORBES, S. The Forbes 400. Forbes, Nova York, v.182, n.6, out., 2008.

FRANK, R. Richistan: a Journey Through the American Wealth Boom. Nova York: Ed. Crown Publishers, 2007.

GAGGERO, J. La fuga de capitales. Documentos de Trabajo, Buenos Aires, n.14, maio 2007.

GODECHOT, O. Working rich. Salaires, bonus et appropriation du profit dans l'industrie financière. Paris: La Découverte, 2007.

GUARDIAN. The Barclays's middle eastern fundrising under fire. Londres, 31 out. 2008.

HARVEY, D. A condição pós-moderna. São Paulo: Ed. Loyola, 1990.

HASELER, S. The Super-Rich, the unjust new world of global capitalism. Londres: Macmillan Press, 2000.

L'EXPANSION. Paris, 27 maio. 2008.

LE MONDE. Un ascenseur doré. Paris, 24 out. 2008.

LIMA, S. A encarnação do otimismo. Portal Exame, 2008. Disponível em: http://portalexame.abril.com.br. Acesso em: 30 out., 2008

LUNDBERG, F. The Rich and the Super-Rich. Nova York: Bantam Books, 1969

MANIÉRE DE VOIR. L'internationale des riches. Le Monde Diplomatique, Paris, n.99, jun./jul., 2008.

MAZLISH, Bruce; MORSS, E. R. A global elite? In CHANDLER, A. D; MAZLISH, Bruce; MORSS, E. R. (Org.) Leviathans: multinational corporations and the new global history. Cambridge: Cambridge University Press, 2005. p.170-186.

MEDEIROS, M. O que faz os ricos ricos. São Paulo: Hucitec, 2005.

NEW YORK TIMES. Nova York, 26 nov. 2006.

NEWSWEEK. Special report: Stealth Wealth. Newsweek, Nova York, v.150, n.2, p.36-65, 2 jul./9 jul. 2007.

Special report: Luxury 2008. Nova York, Newsweek, v.151, n.21, p.42-51, 26 maio/2 jun. 2008.

ONU. The human development report. Nova York: Organização das Nações Unidas. 1996.

PARETO, V. Trattato di sociologia generale. Turim: UTET, [1916] 1988.

PINCON, M.; PINCON-CHARLOT, M. Sociologia da alta burguesia. Sociologias, São Paulo, n.18, jul./dez. 2007.

PIVERT, I. Criação de valor ou extração de lucro? Le Monde Diplomatique Brasil, São Paulo, Instituto Polis, n.20, mar., 2009

POVERTY; FOCUS. Dossiê the Challenge of Inequality. Brasília, International Poverty Centre, jun. 2007.

REICH, R. Supercapitalismo. São Paulo: Campus, 2008.

ROTHKOPT, D. Superclasse. Rio de Janeiro: Agir, 2008.

ROUX, M. Tous milliardaires... Manière de Voir - Dossie l'Internationale des Riches, Paris, n.99, jun./jul., 2008.

SANTOS, J. A. Estrutura e posições de classe no Brasil. Belo Horizonte: Ed. UFMG, 2002.

SCIENCES HUMAINES. Inégalités: le retour dês riches. Paris, n.191, p.33-47, mar., 2008.

SKLAIR, L. The transnational capitalist class. Oxford: Blackwell, 2001. 
TABB, W. The power of the rich. The Montly Review, Nova York, v.58, n.3, 2006.

UNU-WINDER. The world distribution of Household Wealth. Helsinki,FI: United Nations University. 2006.

VEBLEN, T. A teoria da classe ociosa. São Paulo: Ed. Abril, 1983.

WACQUANT, L. J. D. La généralisation de l'insécurité salariale en Amérique: Restructurations d'entreprises et crise de reproduction sociale. Actes de la Recherche en Sciences Sociales, Paris, n.115, dez., 1996.
WAGNER, A. Les classes socials dans la mondialisation. Paris: La Découverte, 2007.

WALDENSTRÖN, D. Why should inequality researchers care about the rich? Bulletin IFC. Basel, Bank for International Settlements, n.28. 2006.

WALL STREET JOURNAL. Nova York, 20 nov. 2008.

WORLD BANK. Equity and development. Washington: 2006.

WRIGHT MILLS, C. The power elite. Oxford: Oxford University Press, 1956. 


\section{WEALTH AND INEQUALITIES}

\section{Antonio David Cattani}

In this paper the main characteristics and meanings of a specific segment of the holders of high fortunes coming from extraction of wealth in the globalized economy are analyzed. Millionaires and billionaires are designated by the financial managers as High net worth individuals (HNWIs). They don't constitute a social class presupposing identity, cohesion and collective mobilization from homogeneous and articulate interests. But, as components of the internationalized dominant sectors they possess high economical and political power with significant impacts on social reality. HNWIs are in the center of the process of acutization of the social and economic inequalities in the last 20 years and they are characterized by three aspects: the) desvinculation of physical dimensions of the capital and absence of national roots; b) personification of fortunes; c) ostentatious standard of living contrasting in a marked way to the remaining of the population. The central argument of this paper is that analyzing the social structure, it is necessary to consider it as an whole, integrated and articulate, the extremes wealth and poverty not being self-explanatory and even less autonomous. Considering the importance of the scale in the wealth ownership, it is possible to understand how it her assures impunity, privileges and power for specific minorities, enlarging the inequalities and the production of the poverty.

KEYWORDS: wealth, power, social classes, social and economic inequalities.

\section{RICHESSE ET INEGALITES}

\section{Antonio David Cattani}

Cet article analyse le sens et les principales caractéristiques d'un segment spécifique de propriétaires de grandes fortunes issues de l'extraction de la richesse dans l'économie mondiale. Les millionnaires et les milliardaires sont désignés par les gestionnaires financiers comme des High net worth individuals (HNWIs). Ils ne forment pas une classe sociale qui suppose une identité, une cohésion et une mobilisation collective à partir d'intérêts homogènes et articulés mais, en tant que composante des secteurs internationalisés dominants, ils possèdent un pouvoir économique et politique élevé ayant des impacts importants sur la réalité sociale. Les HNWIs sont au cœur du processus d'aggravation des inégalités socioéconomiques au cours des 20 dernières années. Trois aspects les caractérisent: a) l'absence de la dimension physique du capital et de liens nationaux; b) la personnification des fortunes; c) des niveaux de vie fastueux qui contrastent nettement avec le reste de la population. L'argument central de cet article est que, lorsqu'on fait l'analyse de la structure sociale, il faut considérer cette dernière comme un tout intégré et articulé, les pôles de richesse et de pauvreté ne sont pas auto explicatifs et bien moins encore autonomes. Si l'on prend en considération l'importance de l'échelle de possession des richesses, il est possible de comprendre comment elle garantit l'impunité, les privilèges et le pouvoir pour des minorités spécifiques tout en augmentant les inégalités et en créant plus de pauvreté.

Mots-CLÉs: richesse, pouvoir, classes sociales, inégalités socioéconomiques.

Antonio David Cattani - Doutor pela Université de Paris I Panthéon-Sorbonne. Professor titular de Sociologia do Departamento de Sociologia e do Programa de Pós-Graduação em Sociologia da UFRGS. Pesquisador 1-A do CNPq. Coordena o GT Desigualdades: Teorias e Conceitos (CNPq). Autor e organizador de livros publicados no Brasil, Argentina, Colômbia, França, Itália e México e Portugal, entre eles, Trabalho e autonomia (Petrópolis, Vozes, 2000) Dicionário Internacional da Outra Economia (Coimbra, Almedina, 2009), Dicionario Latinoamericano de l'otra economia (B.Aires, Editorial Altamira, 2009). Organizador do dossiê "Riqueza e Desigualdades" revista Sociologias no 18, 2007. Recebeu o Prêmio FAPERGS Pesquisador Destaque 2007 e o Prêmio Açorianos 2007 pelo Dicionário de Trabalho e Tecnologia organizado com Lorena Holzmann (Porto Alegre: Editora da UFRGS). www.antoniodavidcattani.net 
